CLINICAL STUDY

\title{
Outcome in patients with adrenal incidentaloma selected for surgery: an analysis of 88 cases investigated in a single clinical center
}

\author{
Jean Pierre Luton ${ }^{1}$, Monique Martinez ${ }^{1}$, Joël Coste $^{2}$ and Jérôme Bertherat ${ }^{1}$ \\ ${ }^{1}$ Clinique des Maladies Endocriniennes et Métaboliques and ${ }^{2}$ Département de Biostatistiques, Hôpital Cochin, and Université René Descartes-Paris V, \\ Paris, France \\ (Correspondence should be addressed to J P Luton, Service des Maladies Endocriniennes et Métaboliques, Hôpital Cochin, 27, rue du Fg-St-Jacques, \\ 75014, Paris, France; Email: jean-pierre.luton@cch.ap-hop-paris.fr)
}

\begin{abstract}
Objective: The study was designed to evaluate the clinical, endocrinological and radiological parameters used to investigate adrenal incidentalomas and select patients for surgery.

Design and Methods: An analysis of 88 consecutive patients with adrenal incidentaloma selected for surgery and investigated in a single clinical center was performed.

Results: Mean ( \pm S.D.) age of the patients was $53 \pm 14$ years. Fourteen (16\%) of the adrenal incidentalomas were malignant tumors ( 2 adrenocortical carcinomas, 3 metastases, 4 adenocarcinomas, 4 sarcomas and 1 mesenchymoma), 10 (11\%) were pheochromocytomas, 32 (36\%) were non-secretory benign adrenal adenomas and the remaining were benign adrenal $(n=8 ; 9 \%)$ or extraadrenal $(n=24 ; 27 \%)$ masses. Endocrinological investigations revealed 1 Conn adenoma, 4 tumors responsible for Cushing's syndrome or silent hypercortisolism and 1 androgen secreting tumor. Abnormalities of endocrine evaluations were observed in the 2 malignant adrenocortical carcinomas. Elevated 24-h urinary metanephrine levels were observed in the 9 pheochromocytomas tested. Complications of surgery occurred in $14 \%$ of the cases. Regardless of the endocrine status, parameters associated with malignant tumors were: older age (mean age of patients harboring malignant tumors vs patients with benign incidentalomas: $62 \pm 17$ years vs $52 \pm 13$ years, $P=0.005$ ), weight loss ( $39 \%$ vs $7 \%, P=0.005)$, and mass diameter greater than $60 \mathrm{~mm}(69 \%$ vs $15 \%, P<0.001)$. By multiple logistic regression analysis malignant tumors were associated with increased age, diameter greater than $60 \mathrm{~mm}$ and bilateral masses.

Conclusion: This study points to a high rate of pheochromocytomas and malignant tumors in patients selected for surgery. This high rate differs from some previous reports and might be explained by the criteria used to select patients for surgery. Among these two groups of tumors, careful systematic endocrinological investigations allow the detection of altered secretion in the vast majority - if not all malignant tumors of adrenal origin and pheochromocytomas. Only 5\% of the incidentalomas below $30 \mathrm{~mm}$ selected for surgery in this study were malignant, in keeping with the use of this criteria as an important parameter to select patients with normal hormonal investigations for careful follow-up.
\end{abstract}

European Journal of Endocrinology 143 111-117

\section{Introduction}

With the increasingly widespread use of highly sensitive imagery, the accidental discovery of an adrenal mass by imaging study performed for an unrelated reason is a frequent clinical problem. The prevalence of an adrenal mass is up to $7.9 \%$ according to autopsy studies and $10.8 \%$ according to CT scan studies $(1-4)$. The so called adrenal incidentalomas are frequently non-hypersecreting adrenal adenomas, but also occur as steroid secreting adenomas, pheochromocytomas as well as primary or secondary malignant tumors. The major potential disorders secondary to the evolution of an adrenal incidentaloma could be related to hypersecretion of steroids or catecholamines, or to tumoral growth or metastasis. As the incidentalomas are usually asymptomatic, the problem for the clinician is to perform the appropriate analysis to diagnose the malignant and the secretory tumors in order to define the correct treatment.

Although several studies have been performed on the diagnosis of adrenal incidentalomas, many diagnostic and therapeutical strategies have been recommended. Most authors agree that larger masses and/or secretory masses should be removed because they are the most likely to be malignant or to cause symptoms secondary 
to steroid or catecholamine hypersecretion. An analysis of the correlation between preoperative investigations and pathological diagnosis performed in 88 consecutive patients studied and operated on during an 18-year period in a single clinical center was performed, in an attempt to define the predictive criteria which would help establish a diagnosis and select the patients for surgery.

\section{Patients and methods}

Two hundred and eight patients with an adrenal incidentaloma were investigated in the Endocrine Department of the Hôpital Cochin from 1978 to 1996. One hundred and eighty of the patients underwent complete clinical, radiological and hormonal evaluation in the department. There were 103 females and 77 males with ages ranging from 13 to 83 years.

The diagnosis was confirmed by pathological examination in ninety-two patients, eighty-eight after surgery, three after percutaneous adrenal biopsy (the final diagnosis was metastasis in the three cases and they were all patients with bilateral incidentalomas but who did not have a previously known malignancy) and one after autopsy (adrenocortical carcinoma). All pathological diagnoses were performed by the same pathologist (Dr A Louvel, Hôpital Cochin). Patients were always selected for surgery when hormonal evaluation revealed a secreting tumor. When the hormonal evaluation did not show hypersecretion, patients were most often selected for surgery when the results of radiological investigations did not allow the firm confirmation of a benign mass (diameter above $3 \mathrm{~cm}$ or non-homogeneous masses were the criteria most often used for this selection) or when a follow-up of the patient was difficult to organize. The 88 patients investigated in our center and operated on were selected for this analysis.

Adrenal incidentalomas were evaluated by an abdominal ultrasound $(n=2)$, abdominal CT scan and/or magnetic resonance imaging $(n=86)$. In the unilateral lesions, the largest diameter was considered. In the patients with a bilateral incidentaloma, the diameter of the largest mass was considered.

\section{Endocrinological studies}

Investigations were performed in the Endocrine department according to a routine standardized procedure. The secretion of glucocorticoids was assessed by measurement of plasma cortisol levels at $0800 \mathrm{~h}$ and $2000 \mathrm{~h}$ and of 24-h urinary free cortisol (UFC). The plasma level of cortisol was assessed at $0800 \mathrm{~h}$ after the overnight dexamethasone (DXM) suppression test ( $1 \mathrm{mg}$ ), and UFC was assessed after low dose ( $2 \mathrm{mg}$ per day) dexamethasone suppression test. Cortisol plasma levels were assessed before and after adrenocorticotropin (ACTH) stimulation test $(\mathrm{ACTH}(1-24), 250 \mu \mathrm{g}$ i.m.). Androgen secretion was evaluated by measurement of plasma testosterone, androstenedione and dehydroepiandrostenedione sulfate (DHEAS), estradiol secretion by the measurement of plasma $17 \beta$-estradiol, mineralocorticoids secretion by the measurement in the supine and upright position of plasma renin activity or plasma renin level and plasma aldosterone. Plasma 17hydroxyprogesterone (170HP) and the 24-h urinary excretions of metanephrines were also assessed. Plasma cortisol was assessed by a competitive protein-binding assay $(5,6)$. The other plasma steroids and urinary cortisol were assessed by specific radioimmunoassays in routine use at the time. Urinary metanephrines were assessed by high performance liquid chromatography (7).

\section{Statistical analysis}

Data are reported as means \pm S.D. Wilcoxon test and Chisquared tests were used to compare groups with and without malignancy. Two tailed $P$ values were used. Odds ratios (OR) and 95\% confidence intervals (CI) were used to describe the association between malignancy and potential risk factors. Unconditional multiple logistic regression models were used to study the effect of several factors simultaneously. A forward stepwise procedure was used to include in the final model only the factors with significant explanation of outcome (enter and remove $P$ values $=0.05$ ). The computations were performed using the SAS package (SAS Institute Inc, Cary, NC, USA, 1990).

\section{Results}

\section{Histological diagnosis and patients' characteristics}

In this group of 88 patients investigated in our center and selected for surgery, $14(16 \%)$ of the lesions were found to be malignant, 10 (11\%) were pheochromocytomas and the remaining were benign masses (Table 1).

These incidentalomas were detected in the following ways: medical check-up for a non-endocrine disorder (31\%), pain syndrome (16\%), gastrointestinal symptoms $(14 \%)$, urinary symptoms (11\%), hepatic symptoms $(7 \%)$, and others $(21 \%)$. Both sexes were almost equally represented (48 females and 40 males). The mean ( \pm S.D.) age was $53 \pm 14$ years, the youngest being 13 and the oldest 80 . There was a greater incidence of benign adrenocortical adenomas and malignant lesions in patients over 50 (Fig. 1). Nine of the patients were diabetics $(10 \%)$ and this parameter did not correlate with the diagnosis of the adrenal mass. Thirty-eight patients had hypertension (43\%) while this was present in only $30 \%$ of pheochromocytomas. Weight loss greater than $10 \%$ was found in ten patients $(11 \%)$. Seven patients had a previous history of neoplasm $(8 \%)$, only one of whom had a metastatic adrenal lesion. This 
Table 1 Adrenal incidentalomas etiologies.

\begin{tabular}{lrr}
\hline Mass etiology & Number & $\%$ \\
\hline Adrenal cortex & & \\
Non-functional adrenocortical adenoma & 32 & 36 \\
Silent hypercortisolism adenoma & 2 & 2 \\
Cushing's adenoma & 1 & 1 \\
Aldosterone producing adenoma & 1 & 1 \\
Adrenal hyperplasia & 4 & 4.5 \\
Adrenocortical carcinoma & 2 & 2 \\
& & \\
Adrenal medulla & & \\
Pheochromocytoma & 10 & 11 \\
& & 3 \\
Extra adrenal masses & & 5 \\
Metastases & 3 & 1 \\
Adenocarcinoma & 4 & 5 \\
Malignant mesenchymoma & 1 & 6 \\
Sarcoma & 4 & 2 \\
Neurofibroma & 5 & 7 \\
Schwannoma & 2 & 8 \\
Lymphangioma & 6 & 1 \\
Hematoma & 7 & 3 \\
Bronchogenic cyst & 1 & 3 \\
Miscellaneous lesions & 3 & \\
\end{tabular}

patient had a previously known colon cancer but the adrenal incidentaloma was a kidney cancer. Therefore, in this group of patients selected for surgery we did not observe any adrenal incidentaloma corresponding to metastases of a previously known cancer.

Pre-operative complications were observed in 4 patients: 3 patients with pheochromocytoma (hypertensive crisis, supraventricular arythmia, and death from cardiac arrest) and 1 patient with adrenocortical carcinoma (hemorrhage). Postoperative complications were observed in 8 patients: 6 patients with benign incidentaloma ( 2 abscess, 1 pneumothorax, 1 secondary peritoneal bleeding, 2 pulmonary embolism) and 2 patients with malignant disease (1 pancreatic fistula and 1 pneumonia). No complication was observed in 76 $(86 \%)$ of the patients.

\section{Endocrinological results (Table 2)}

Endocrinological studies revealed a hyperaldosteronism corresponding to an aldosterone producing adenoma, and one case of Cushing's syndrome corresponding to one adrenocortical adenoma. Silent hypercortisolism, defined as abnormal cortisol rhythm associated with an insufficient cortisol suppression during low dose dexamethasone test was observed in three patients, two adrenocortical adenomas and one adrenocortical carcinoma. The only endocrine alteration observed in the second adrenocortical carcinoma case was a very slight increase in plasma testosterone levels in a female patient $(0.7 \mathrm{ng} / \mathrm{ml})$. Taken singly, an abnormal cortisol rhythm or an abnormal overnight or low dose dexamethasone test was not specific to an adrenal lesion. They were observed in adrenocortical masses as well as in nonadrenal masses. Of the four adrenal hyperplasias, two were purely histological with normal basal $170 \mathrm{HP}$, the two others showed a clear increase in basal 170HP. DHEAS levels were low in 56 cases $(64 \%), 26$ of which $(46 \%)$ corresponded to extra-adrenal masses. A moderate increase in plasma testosterone and $17 \beta$-estradiol was found respectively in 7 and $8 \%$ of the cases, none of which had any secreting lesions except for an adrenocortical carcinoma. A decrease in the cortisol response to ACTH stimulation was found in five cases; one of

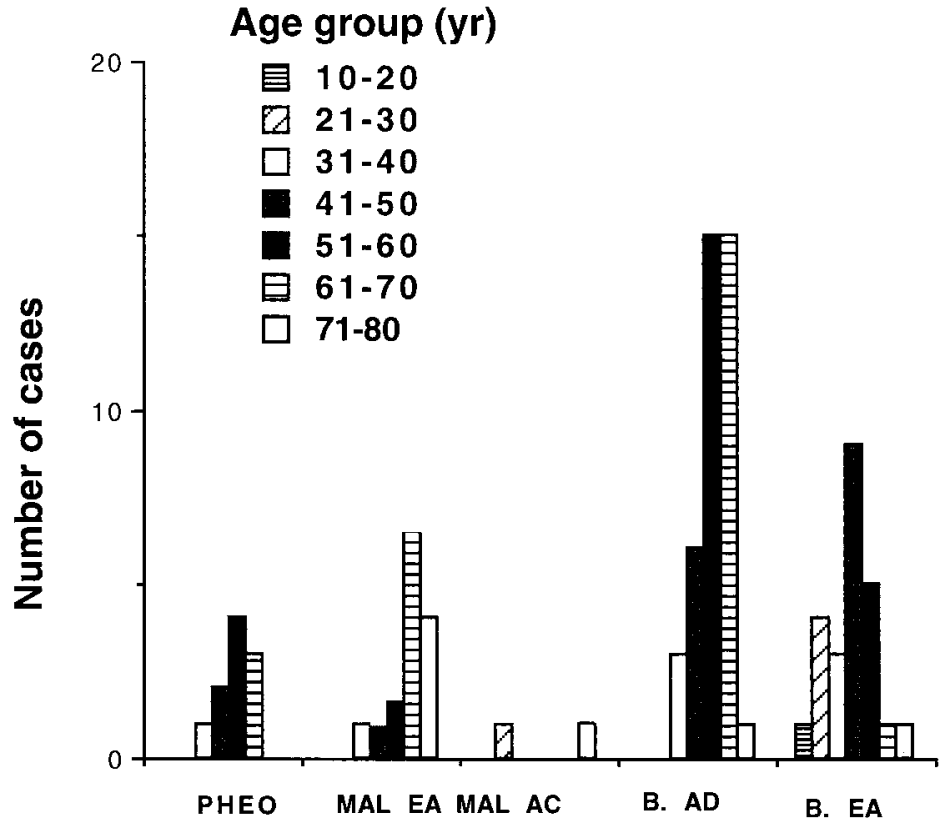

Figure 1 Distribution of adrenal incidentaloma according to patient age and diagnosis. The number of patients classified by age group and diagnosis is shown. PHEO, pheocromocytoma, MAL. EA, maligant extra-adrenal tumor; MAL. AC, malignant adrenocortical carcinoma; B. AD, benign adrenal tumor; B. EA, benign extra-adrenal tumor. 
Table 2 Endocrinological investigations of secreting tumors and adrenal hyperplasia.

\begin{tabular}{|c|c|c|c|c|c|c|c|c|c|c|}
\hline Tumor & Sex & $\begin{array}{c}\text { Cortisol } \\
\text { at } \\
0800 \mathrm{~h} \\
(\mathrm{ng} / \mathrm{ml})\end{array}$ & $\begin{array}{c}\text { Cortisol } \\
\text { at } \\
2000 \mathrm{~h} \\
(\mathrm{ng} / \mathrm{ml})\end{array}$ & $\begin{array}{c}\underset{(\mu \mathrm{UFC}}{\mathbf{U}} \mathbf{2 4 h})\end{array}$ & $\begin{array}{c}\text { Cortisol } \\
\text { after } \\
\text { overnight } \\
\text { DXM text } \\
\text { (ng/ml) }\end{array}$ & $\begin{array}{c}\text { UFC after } \\
\text { low dose } \\
\text { DMX test } \\
(\mu \mathrm{g} / 24 \mathrm{~h})\end{array}$ & $\begin{array}{c}\text { Cortisol } \\
\text { after } \\
\text { stimulation } \\
\text { test } \\
(\mathrm{ng} / \mathrm{ml})\end{array}$ & $\begin{array}{c}17 \text { OHP } \\
(\mathrm{ng} / \mathrm{ml})\end{array}$ & $\begin{array}{l}\text { DHEAS } \\
(\mu \mathrm{g} / \mathrm{ml})\end{array}$ & $\begin{array}{l}\text { Testosterone } \\
(\mathrm{ng} / \mathrm{ml})\end{array}$ \\
\hline CA & $\mathrm{F}$ & 118 & 130 & 131 & 311 & 254 & 430 & & & 0.35 \\
\hline AA & $\mathrm{F}$ & 111 & 13 & 39 & $<10$ & 9 & 202 & 0.65 & 0.66 & 0.18 \\
\hline SH & $\mathrm{F}$ & 238 & 152 & 50 & 51 & 13 & & 0.17 & 0.17 & 0.06 \\
\hline $\mathrm{SH}$ & $\mathrm{F}$ & 132 & 129 & 90 & & 22 & 643 & 0.4 & 0.7 & 0.2 \\
\hline$A C$ & $\mathrm{~F}$ & 155 & 92 & 50 & & & 252 & $<0.1$ & 0.58 & 0.7 \\
\hline$A C$ & $\mathrm{~F}$ & 210 & 218 & 43 & 246 & 51 & 247 & 1.1 & 5.2 & 0.6 \\
\hline $\mathrm{AH}$ & $M$ & 134 & 27 & 46 & $<10$ & 14 & 225 & 64.9 & 1.05 & 8.02 \\
\hline $\mathrm{AH}$ & $\mathrm{F}$ & 81 & & 358 & & & 87 & 27.1 & 0.39 & 1.53 \\
\hline $\mathrm{AH}$ & $\mathrm{M}$ & 126 & 53 & 52 & 12 & 8 & 287 & 0.5 & 0.16 & 4.36 \\
\hline $\mathrm{AH}$ & $\mathrm{M}$ & 120 & 43 & 25 & 24 & 9 & 290 & 3.88 & 0.5 & 6 \\
\hline
\end{tabular}

CA: Cushing's adenoma, AA: aldosterone producing adenoma, SH: silent hypercortisolism, AC: adrenocortical carcinoma, AH: adrenal hyperplasia.

Plasma cortisol normal value $0800 \mathrm{~h}: 100-200 \mathrm{ng} / \mathrm{ml}$, UFC: normal value $<90 \mu \mathrm{g} / 24 \mathrm{~h}$, plasma cortisol after $1 \mathrm{mg}$ DXM supression test: normal value $<40 \mathrm{ng} / \mathrm{ml}$, UFC after $2 \mathrm{mg} /$ day DXM during 2 days: normal value $<10 \mu \mathrm{g} / 24 \mathrm{~h}$, plasma cortisol after $250 \mu \mathrm{g} \mathrm{ACTH}(1-24)$ i.m. injection: normal value $>210 \mathrm{ng} / \mathrm{ml}, 17 \mathrm{OHP}$ normal value in male: $1.5-2.8 \mathrm{ng} / \mathrm{ml}$, in female: $0.7-3.5 \mathrm{ng} / \mathrm{ml}$, DHEAS normal value in male: $0.8-3.3 \mu \mathrm{g} / \mathrm{ml}$, in female: $0.9-2.8 \mu \mathrm{g} / \mathrm{ml}$, plasma testosterone normal value in male: $4-10 \mathrm{ng} / \mathrm{ml}$, in female $0.2-0.6 \mathrm{ng} / \mathrm{ml}$. For the aldosterone producing adenoma (AA) renin plasma levels were undetectable on clinostatism and orthostatism, aldosterone plasma level was $176 \mathrm{pg} / \mathrm{ml}$ on clinostatism (normal value $24-68 \mathrm{pg} / \mathrm{ml}$ ).

these was a severe adrenal insufficiency (cortisol peak $87 \mathrm{ng} / \mathrm{ml}$ ) and was a case of adrenal congenital hyperplasia. In the other four cases, the insufficiencies were moderate (cortisol peak between 146 to $202 \mathrm{ng}$ / $\mathrm{ml}$ ) and corresponded to unilateral lesions. In the nine pheochromocytomas tested, an increased 24-h urinary metanephrine level was observed.

\section{Morphological results}

The average size of the 88 incidentalomas was $50 \pm 30 \mathrm{~mm}$. Eighteen lesions $(20 \%)$ were smaller than $30 \mathrm{~mm}$, fifty $(57 \%)$ were between 30 and $60 \mathrm{~mm}$, and twenty $(23 \%)$ were larger than $60 \mathrm{~mm}$. The size distribution according to the pathological diagnosis is shown in Fig. 2. It must be noted that CT scan, compared with measurement by the pathologist, led to an underestimation of lesion size in $63 \%$ of the cases (with a 10\% margin of error).

\section{Parameters associated with malignancy}

Mean patient age was higher in those harboring malignant masses $(62 \pm 17$ years vs $52 \pm 13$ years, $P=0.005)$. Weight loss was more frequent in patients with malignancy $(39 \%)$ than in the others $(7 \%$, $P=0.005)$. Bilateral adrenal masses were more frequent in neoplastic than in benign masses $(23 \%$ vs $12 \%)$, but this was not significant $(P=0.3)$. The malignant adrenal masses were in the above $60 \mathrm{~mm}$ group in $69 \%$ of the cases, while only $15 \%$ of the benign masses were above $60 \mathrm{~mm}(P<0.001)$. A size above

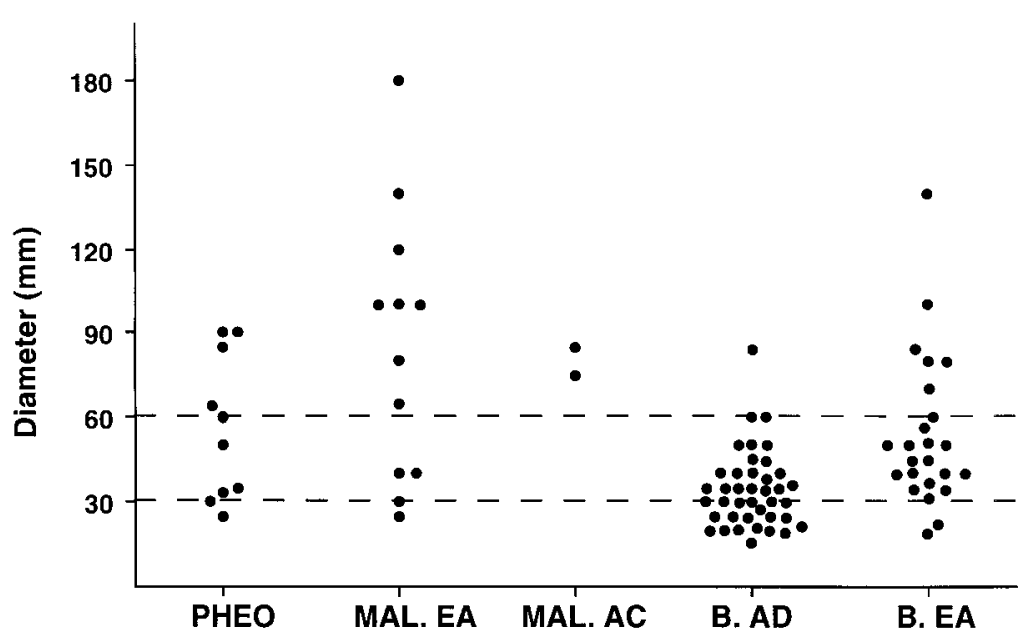

Figure 2 Adrenal incidentaloma size distribution according to diagnosis. The maximal diameter of each incidentaloma as assayed by preoperative investigation is shown according to diagnosis. The diagnosis abbreviations are the same as in Fig. 1. 
$60 \mathrm{~mm}$ was significantly associated with malignancy. The other parameters were not significantly associated with malignancy. Excluding the secreting tumors from the analysis did not significantly change the results (data not shown).

The parameters independently associated with malignancy were: bilaterality (adjusted OR: 11.3; CI: $1.3-$ 94.8), tumor size greater than $60 \mathrm{~mm}$ (adjusted OR: 12.7; CI: 2.5-64.1), age (adjusted OR: 0.7; CI: 0.5-0.9) and squared age (adjusted OR: 1.004; CI: 1.001$1.007)$. A second order polynomial curve $(-0.35 \mathrm{age}+$ $\left.0.0041 \mathrm{age}^{2}\right)$ most accurately fitted the relationship between age and the risk of malignancy, reflecting an excess risk at the two extremities of adult lifespan (below 30 and above 60 years).

\section{Discussion}

The 88 adrenal incidentalomas of this study illustrate the various differential diagnoses of incidentally discovered adrenal masses. These incidentalomas were diagnosed as benign and secreting adrenocortical lesions in 5\%, pheochromocytomas in $11 \%$, and malignant lesions in $16 \%$ (2\% adrenocortical carcinomas, 3\% metastases and $11 \%$ malignant extra adrenal masses) of the patients. The frequency of pheochromocytoma, benign and malignant adrenocortical lesion is quite similar to some previous reports but the rate of malignant tumors is often lower than in our study $(2,3$, 8-13). This might be explained by the selection procedure of the patients before surgery. Metastases were reported previously at highly variable rates, that could rise as high as $52 \%$ in neoplasic patients $(9,11$, 13-17). It should be noted that bilateral masses are notable for their extremely variable etiologies in our study. Bilateral masses in our patients proved to be metastases in a minority of the cases. However, a very high proportion of metastases are bilateral in the patients selected for surgery and the 3 patients in whom a percutaneous cytodiagnostic was performed. We observed a high proportion of malignant extra adrenal masses, which were located in the adrenal space and included the adrenal gland because of their great size. These tumors, which have not been much described, are real traps for diagnosis. Although they do not meet most author's definition of an adrenal incidentaloma, they nonetheless have the appearance of incidentalomas and involve the same difficulties for diagnosis. The average age of the 88 patients, at 53 , is lower than those usually reported (8-21). Hypertension, which was found in $43 \%$ of the patients, is also often reported in the literature at a higher frequency than in the overall population. The prevalence of diabetes is not any higher, contrary to what is generally assumed.

The diagnosis of secreting tumors requires careful endocrinological investigation. The assay of 24-h urinary free cortisol and a dexamethasone suppression test are required for the diagnosis of cortisol secreting adrenocortical tumors. The criteria defining silent hypercortisolism adrenocortical adenoma are difficult to establish. Taking this into account, only one abnormality of the adrenal axis does not seem to be enough for a diagnosis of silent hypercortisolism. Indeed, abnormalities of the adrenal axis were observed in some cases of non-adrenocortical masses (22). Some authors have reported silent hypercortisolism in up to $10 \%$ of adrenal incidentalomas, using various criteria (23-31). We found a much lower rate, of 3\%, using as a definition a combination of abnormal cortisol rhythm and absence of cortisol suppression during low dose dexamethasone test. The radiocholesterol scintigraphy could be put to good use here, as a helpful tool for diagnosis (32-34). Concerning the level of DHEAS, it is reported as being low in the benign adrenocortical lesion and high in adrenocortical carcinoma $(35,36)$. We did not observe this result. It should be noted that there is no correlation in any of these studies nor in ours between the level of DHEAS and the age of the patients, which could have a part in these negative results (37). This suggests that the assay of DHEAS is not very helpful for routine investigation of adrenal incidentaloma. However, elevated DHEAS levels, in particular when associated with increased testosterone levels, might suggest a malignant adrenocortical tumor. In the presence of bilateral adrenal lesions, an ACTH stimulation test should be performed to detect an adrenal insufficiency. This was found in two cases of adrenal metastases diagnosed by percutaneous cytodiagnosis (data not shown). For bilateral masses, plasma levels of $170 \mathrm{HP}$ are also useful in the detection of congenital adrenal hyperplasia, as in two cases studied here and in previous reports (38-40). It is necessary to measure urinary metanephrines to detect a pheochromocytoma that is usually asymptomatic in patients with an adrenal incidentaloma. Considering the high rate of pheochromocytoma (11\%) and the potential dramatic consequences of catecholamine hypersecretion, a urinary 24-h metanephrine assay should be recommended in patients presenting with adrenal incidentaloma, in particular when surgery is chosen. In our study, 24-h urinary metanephrines were always elevated when assayed in pheochromocytomas. Considering the high complication rate observed during surgery of pheochromocytomas in this study, the preoperative diagnosis of pheochromocytoma is very important. Careful endocrinological evaluation in our study allowed the diagnosis of all the adrenocortical hypersecretory or pre-toxic tumors and pheochromocytomas. The results of endocrinological investigations revealed cortisol or testosterone hypersecretion in the two adrenocortical carcinomas. Nevertheless, only a slightly increased testosterone level was observed in one of these adrenocortical carcinomas which might have been diagnosed as a non-secretory tumor if testosterone levels had not been assayed. 
Except for adrenocortical carcinoma, endocrinological evaluation does not contribute very much to the diagnosis of malignant tumors. Malignancy was significantly associated with age, weight loss, and increased tumor size. After multivariate analysis, bilaterality was also associated with malignancy. The rate of malignant tumors increased in patients older than 60 years. Concerning the size of the adrenal masses, it was impossible to find a threshold below which a lesion would be benign. For instance, a 25$\mathrm{mm}$ diameter tumor was a malignant sarcoma. But a diameter above $60 \mathrm{~mm}$ was significantly associated with malignant tumors. This increase of malignancy with size has been reported by many authors $(3,11$, 13, 21), although some malignant lesions smaller than $3 \mathrm{~cm}$, particularly adrenocortical carcinoma, have been reported $(9,13,41)$. It must be noted that the incidentaloma size determined by imagery should be assessed with care because size was often underestimated in our study, as well as in the literature (42). In this study, almost all incidentalomas smaller than $30 \mathrm{~mm}$ were benign masses (17/18). Therefore, surgery might not have been performed in the vast majority of such patients but in this case a careful follow-up is mandatory. With incidentaloma size between 30 and $60 \mathrm{~mm}$, the percentage of malignant tumors increases and selection of the patients to operate or not is more difficult. Laterality, age, and weight loss together with a careful analysis of radiological investigations are important parameters to take into account. Other criteria, such as, for instance, the lipid content, could be considered as an important parameter for the diagnosis (13-16, 41, 43-49). The latest advances in radiological and nuclear imaging technology will probably be extremely helpful to clinicians in handling adrenal incidentalomas (49-52).

In conclusion, this study of 88 adrenal incidentalomas evaluated and operated on in a single center illustrates the relatively high rate of malignant tumors (about 16\%) and pheochromocytomas (about 10\%) which both require a specific treatment, including, in most cases, surgical removal. Careful endocrinological evaluation of steroids as well as metanephrine secretion allow one to identify the secreting tumors. Malignancy is often difficult to exclude and should be strongly suspected with increased age, weight loss, bilateral masses and diameter above $60 \mathrm{~mm}$. Considering that even with the recent progress in adrenal surgery complications can always occur ( $14 \%$ of our cases in this retrospective study), a careful selection of the patients is important. A unilateral non-secreting mass below $30 \mathrm{~mm}$ would rarely be a malignant tumor $(1 / 18,5 \%$, in our study). The small incidentalomas might be selected for follow-up when careful analysis of clinical, hormonal and radiological investigations do not show any signs suggestive of a malignant tumor.

\section{Acknowledgements}

We thank Prof. A Bonnin (Department of Radiology, Hôpital Cochin), Prof. YL Chapuis (Department of Endocrine Surgery, Hôpital Cochin), Dr A Louvel and Prof. Forest (Department of Pathology, Hôpital Cochin), Drs B Guilhaume, L Billaud, H Mosnier-Pudard, C Bremont and Prof. X Bertagna (Department of Endocrinology, Hôpital Cochin) for their precious collaboration in the investigation of the patients, and S Sutton for helpful comments on the manuscript.

\section{References}

1 Caplan RH, Strutt PJ \& Wickus GG. Subclinical hormone secretion by incidentally discovered adrenal masses. Archives of Surgery 1994129 291-296.

2 Prinz RA, Brooks MH, Churchill R, Graner JL, Lawrence AN, Paloyan E et al. Incidental asymptomatic adrenal masses detected by computed tomographic scanning. Journal of the American Medical Association 1982248 701-704.

3 Herrera MF, Grant CS, Van Heerden JA, Sheedy PF \& Ilstrup DM. Incidentally discovered adrenal tumors: an institutional perspective. Surgery $19911101014-1021$.

4 Kley HK, Wagner H, Jaresch S, Jungbluth R \& Schlaghecke R. Endokrin inaktive nebennierentumoren. In Moderne Diagnostik und therapeutische Strategien bei Nebennierenerkrankungen, pp 189197. Eds B Allolio \& HM Schulte. Stuttgart, New York: Schattauer, 1990.

5 Vidal-Trecan G, Laudat MH, Thomopoulos P, Luton JP \& Bricaire H. Urinary free corticoids: an evaluation of their usefulness in the diagnosis of Cushing's syndrome. Acta Endocrinologica 198315 110-115.

6 Barrou Z, Guiban D, Maroufi A, Fournier C, Dugué MA, Luton JP et al. Overnight dexamethasone suppression test: comparison of plasma and salivary cortisol measurement for the screening of Cushing's syndrome. European Journal of Endocrinology 1996134 93-96.

7 Revol A, Comoy E, Forzy G, Garnier JP, Gerhardt MF, Hirth C et al. Méthodes recommandées pour le dosage des catécholamines et de leur métabolites dans l'urine. Annales de Biologie Clinique 199452 625-637.

8 Terzolo MG, Osella G, Ali A, Reimondo G, Borretta G, Magro GP et al. Adrenal incidentaloma, a five year experience. Minerva Endocrinologica 199520 69-78.

9 Aso Y \& Homma Y. A survey of incidental adrenal tumors in Japan. Journal of Urology 1992147 1478-1481.

10 Cook DM \& Loriaux CL. The incidental adrenal mass. American Journal of Medicine 1996101 88-95.

11 Gajraj H \& Young AE. Adrenal incidentaloma. British Journal of Surgery $199380422-426$.

12 Krane NK. Clinically unsuspected pheochromocytomas. Experience of Henry Ford Hospital and review of the literature. Archives of Internal Medicine 1986146 54-57.

13 Kloos RT, Gross MD, Francis IR, Korobkin M \& Shapiro B. Incidentally discovered adrenal masses. Journal of Clinical Endocrinology and Metabolism 199516 460-484.

14 Krestin GP, Steinbrich W \& Friedmann G. Adrenal masses: evaluation with fast gradient-echo MR imaging and Gd-DTPAenhanced dynamic studies. Radiology 1989171 675-680.

15 Katz R \& Shirkhoda A. Diagnostic approach to incidental adrenal nodules in the cancer patient. Results of clinical, radiologic, and fine-needle aspiration study. Cancer 198555 1995-2000.

16 Krestin G, Friedmann G, Fischbach R, Neufang KFR \& Allolio B. Evaluation of adrenal masses in oncologic patients: dynamic contrast-enhanced MR vs CT. Journal of Computer Assisted Tomography 199115 104-110. 
17 Candel A, Gattuso P, Reyes CV, Prinz RA \& Castelli MJ. Fine-needle aspiration biopsy of adrenal masses in patients with extraadrenal malignancy. Surgery 1993114 1132-1136.

18 Dominguez-Gadea L, Diez L, Bas C \& Crespo A. Differential diagnosis of solid adrenal masses using adrenocortical scintigraphy. Clinical Radiology $199449796-799$.

19 Kobayashi S, Seki T, Nonomura K, Gotoh T, Togashi M \& Koyanagi T. Clinical experience of incidentally discovered adrenal tumor with particular reference to cortical function. Journal of Urology $19931508-12$.

20 Angeli A, Osella G \& Terzolo M. Adrenal incidentaloma: an overview of clinical and epidemiological data from the national Italian study group. Hormone Research 199747 279-283.

21 Copeland PM. The incidentally discovered adrenal mass. Annals of Internal Medicine 198398 940-945.

22 Gold PW, Loriaux DL \& Roy A. Responses to corticotropinreleasing hormone in the hypercortisolism of depression and Cushing's disease. Pathophysiologic and diagnostic implications. New England Journal of Medicine 1986314 1329-1335.

23 Noritake M, Moritomo K, Kosano H, Nemoto Y, Kugai N, Takao M et al. A case of asymptomatic cortisol producing adrenal adenoma. Endocrinologia Japonica 199239 19-24.

24 Cugini P, Campisi C, Castagna G, Batistti P, Di Palma L, Coppola A et al. Pre-Cushing's syndrome: a case report. Endocrinologia Japonica $199239407-411$.

25 Suzuki H, Shibata H, Maruyama T, Ishimura Y \& Saruta T. Significance of steroidogenic enzymes in the pathogenesis of hyperfunctioning and non-hyperfunctioning adrenal tumor Steroids $19956042-47$.

26 Ambrosi B, Re T, Passini E, Peverelli S, Sartorio A \& Colombo P. Aspetti clinici e preclinici della sindrome di Cushing surrenalica. Minerva Endocrinologica $19952039-47$.

27 Beyer HS \& Doe RP. Cortisol secretion by an incidentally discovered non functional adrenal adenoma. Journal of Clinical Endocrinology and Metabolism 198562 1317-1321.

28 Reicke M, Nieke J, Krestin GP, Saeger X, Allolio B \& Winkelmann W. Preclinical Cushing's syndrome in adrenal incidentalomas: comparaison with adrenal Cushing's syndrome. Journal of Clinical Endocrinology and Metabolism 199275826 832.

29 Tojo K, Abe A, Sato S, Hamaguchi A, Kato N, Furuta N et al. The incidentally discovered asymptomatic cortisol-producing adrenal adenoma pre-Cushing's syndrome. Jikeikai Medical Journal 1995 42 93-101.

30 Tsuboi Y, Ishikawa SE, Fujisawa G, Okada K \& Saito T. Possible pre-Cushing's syndrome due to an adrenal adenoma incidentally discovered. Endocrine Journal 199542 509-516.

31 Rosen HN \& Swartz SL. Subtle glucocorticoid excess in patients with adrenal incidentaloma. American Journal of Medicine 1992 92 213-216.

32 Delemer B, Gibold C, Caron J, Liehn JC \& Delisle MJ. Place de la scintigraphie corticosurrénalienne dans l'exploration des incidentalomes. Annals of Endocrinology 199253 147-152.

33 Francis IR, Gross MD, Shapiro B, Korobkin M \& Quint LE. Integrated imaging of adrenal disease. Radiology 1992 184 1-13.

34 Gross MD, Shapiro B, Francis IR, Glaze MG, Bree RL, Arcomano RA et al. Scintigraphic evaluation of clinically silent adrenal masses. Journal of Nuclear Medicine 199435 1145-1151.

35 Flecchia D, Mazza E, Carlini M, Blatto A, Olivieri F, Serra G et al. Reduced serum levels of dehydroepiandrosterone sulphate in adrenal incidentalomas: a marker of adrenocortical tumour. Clinical Endocrinology 199542 129-134.

36 Osella G, Terzolo M, Borreta G, Magro G, Ali A, Olivieri F et al. Endocrine evaluation of incidentally discovered adrenal masses (incidentalomas). Journal of Clinical Endocrinology and Metabolism $1994791532-1539$.

37 Young J \& Schaison G. Que savons-nous de la DHEA? Revue Française d'Endocrinologie Clinique, Nutrition et Metabolisme 1996 37 390-398.

38 Bathia V, Mishra SK, Gupta RK \& Gandhi S. Adrenal tumor complicating untreated 21-hydroxylase deficiency in a 5-year-old boy. Archives of Pediatrics and Adolescent Medicine 1994148 994995.

39 Jaresch S, Kornely E, Kley HK \& Schlaghecke R. Adrenal incidentaloma in patients with homozygous or heterozygous congenital adrenal hyperplasia. Journal of Clinical Endocrinology and Metabolism 199274 685-689.

40 Mantero F, Masini AM, Opocher G, Giovagnetti M \& Arnaldi G. Adrenal incidentaloma: an overview of hormonal data from the national Italian study group. Hormone Research $199747284-$ 289.

41 Leroy-Willis A, Bittoun J, Luton JP, Louvel A, Lefevre JE, Bonnin A et al. In vivo $\mathrm{MR}$ spectroscopic imaging of the adrenal glands: distinction between adenomas and carcinomas larger than $15 \mathrm{~mm}$ based on lipid content. American Journal of Roentgenology $1989153771-773$.

42 Cerfolio RJ, Vaughan ED, Brennan TG \& Hiverla ER. Accuracy of computed tomography in predicting adrenal tumor size. Surgery $1993176307-309$.

43 Berland LL, Koslin DB, Kenney PJ, Stanley RJ \& Lee JY. Differentiation between small benign and malignant adrenal masses with dynamic increment CT. American Journal of Roentgenology 1988151 95-101.

44 Lee MJ, Hahn PF, Papanicolaou N, Agglin TK, Saisi S, Mueller PR et al. Benign and malignant adrenal masses: CT distinction with attenuation coefficients, size, and observer analysis. Radiology $1991179415-418$.

45 Miyake H, Maeda H, Tashiro M, Susuki K, Nagatomo H, Aikawa H et al. CT of adrenal tumor: frequency and clinical significance of low-attenuation lesions. American Journal of Roentgenology 1989 152 1005-1007.

46 Leroy-Willis A, Roucayrol JC, Luton JP, Courtieu J. Niensenbaum $\mathrm{N} \&$ Louvel A. In vitro adrenal cortex lesion characterization by NMR spectroscopy. Magnetic Resonance Imaging 19875 339-344.

47 Hussain S, Belldegrun A, Seltzer SE, Richie JP, Gittes RF \& Abrams HL. Differentiation of malignant from benign adrenal masses: predictive indices on computed tomography. American Journal of Roentgenology 1985144 61-65.

48 Dunnick NR, Heaston D, Halvorsen R, Moore AV \& Korobkin M. CT appearance of adrenal cortical carcinoma. Journal of Computer Assisted Tomography $19826978-982$.

49 Lee MJ, Mayo-Smith WW, Hahn PE, Goldberg MA, Boland GW, Saini S et al. State-of-the-art MR imaging of the adrenal gland. Scientific Exhibit 199414 1015-1032.

50 Tsushima T, Ishizaka $\mathrm{H}$ \& Matsumoto M. Adrenal masses: differentiation with chemical shift, fast low-angle shot MR imaging. Radiology 1993186 705-709.

51 Mitchell DJ, Crovello M, Matteucci T, Petersen RO \& Miettinen MM. Benign adrenocortical masses: diagnosis with chemical shift MR imaging. Radiology 1992185 345-351.

52 Boland GW, Goldberg MA, Lee MJ, Mayo-Smith WW, Dixon J, McNicholas MM et al. Indeterminate adrenal mass in patients with cancer: evaluation at PET with 2-F-18-fluoro-2-deoxy-Dglucose. Radiology 1995194 131-134.

Received 2 September 1999

Accepted 17 March 2000 